\title{
Effects of Delayed Sample Processing on Determination of Total and High Molecular Weight (HMW) Adiponectin in Serum and Plasma: A Pilot Study
}

\author{
Choaping $\mathrm{Ng}^{1 *}$, Felicity J Rose ${ }^{1,2^{*}}$, Sahar Keshvari ${ }^{1}$, Marina M Reeves ${ }^{3}$, Goce Dimeski ${ }^{4,5}$, Ingrid J Hickman ${ }^{1,6}$, Jonathan \\ P Whitehead ${ }^{1}$ \\ ${ }^{1}$ Mater Research Institute-University of Queensland, Translational Research Institute, Brisbane, Australia \\ ${ }^{2}$ University of Queensland Diamantina Institute, Translational Research Institute, Brisbane, Australia \\ ${ }^{3}$ Cancer Prevention Research Centre, School of Public Health, University of Queensland, Brisbane, Australia \\ ${ }^{4}$ School of Medicine, University of Queensland, Brisbane, Australia \\ ${ }^{5}$ Department of Chemical Pathology, Princess Alexandra Hospital, Brisbane, Australia \\ ${ }^{6}$ Department of Nutrition and Dietetics, Princess Alexandra Hospital, Brisbane \\ Correspondence: Jonathan P Whitehead, 37 Kent Street, Level 4, Translational Research Institute, Brisbane, \\ Queensland, 4102, Australia. Email: jon.whitehead@mater.uq.edu.au \\ *Contributed equally
}

Received: March 8, 2016 Accepted: March 24, 2016 Online Published: June 7, 2016

doi:10.5539/ijc.v8n3p19 URL: http://dx.doi.org/10.5539/ijc.v8n3p19

\begin{abstract}
Adiponectin is a beneficial adipocyte-secreted hormone, which circulates in a variety of multimeric forms termed low and high molecular weight (LMW/HMW). Effectiveness of clinical therapeutic trials which target adiponectin rely on accurate determination of circulating total and HMW adiponectin levels but the accuracy may be influenced by variations in sample handling processes. The aim of this pilot study was to investigate the effects of delayed processing of blood samples on the concentration of total and HMW adiponectin.

Materials and Methods: Fasting blood samples were collected for analysis of total and HMW adiponectin concentrations in EDTA plasma and serum from eight healthy participants. Samples were centrifuged post $15 \mathrm{~min}$ storage at $4^{\circ} \mathrm{C}$ as the comparative 'ideal' method or after up to $72 \mathrm{~h}$ of refrigerated storage or $6 \mathrm{~h}$ at room temperature. Total and HMW adiponectin concentrations were measured by ELISA.

Results: Under ideal handling conditions measurements of total and HMW adiponectin concentrations were significantly higher in serum than in plasma (mean difference: $-1.3 \mu \mathrm{g} / \mathrm{mL}$ [95\% CI: $-1.6,-1.0], \mathrm{p}<0.001$; and, -0.6 $\mu \mathrm{g} / \mathrm{mL}$ [95\% CI: $-0.7,-0.5], \mathrm{p}<0.001$, respectively). Storage of blood samples at $4^{\circ} \mathrm{C}$ for $72 \mathrm{~h}$ resulted in significant reductions in concentration of total adiponectin in serum (mean difference: $-1.4 \mu \mathrm{g} / \mathrm{mL}$ [95\% CI: $-2.0,-0.8], \mathrm{p}=0.001$ ) and HMW adiponectin in plasma (mean difference: $-0.6 \mu \mathrm{g} / \mathrm{mL}$ [95\%CI: $-0.9,-0.2], \mathrm{p}=0.007$ ), compared with ideal conditions. Further analysis of serum samples showed a significant decrease in total adiponectin concentration after $6 \mathrm{~h}$ storage at $4^{\circ} \mathrm{C}$ (mean difference: $-1.4 \mu \mathrm{g} / \mathrm{mL}$ [95\% CI: $\left.-2.0,-0.8\right], \mathrm{p}=0.001$ ) compared with ideal conditions.
\end{abstract}

Conclusions: Delayed processing of samples may have differential effects on the concentration of total and HMW adiponectin in serum or plasma. Larger studies are warranted for clinical intervention trials.

Keywords: adipokines, adiponectin, protein multimerisation, protein stability

\section{Introduction}

Optimised and standardised handling processes and conditions for blood collection and sample storage for accurate "true" concentration estimation of analytes are essential for accurate clinical decisions. However, logistical realities can fall far short of these ideals. Given the variability that may be present in handling of samples, particularly in trials involving sample collection and processing across multiple centres, there has been considerable interest in determining the stability of circulating adiponectin and other analytes in clinical samples under different handling processes and conditions. Studies designed to establish the stability of factors such as cytokines (Keustermans, Hoeks, Meerding, Prakken, \& de Jager, 2013), hormones (Oddoze, Lombard, \& Portugal, 2012) and small molecules (Mechanic et al., 
2013) have produced variable results that reflect a combination of differences between analytes, protocols and methods of detection. For example, a recent study looking at stability from peptide fingerprinting using Mass Spectrometry found a high level of stability for many of the proteins studied whereas methods that require intact proteins, or at least intact antigenic regions such as ELISAs, may be less forgiving (Zimmerman, Li, Yarbrough, Slebos, \& Liebler, 2012).

In this pilot study the protein of interest, adiponectin, is a cytokine-like protein secreted by adipose tissue. Adiponectin has insulin-sensitising, anti-atherogenic, anti-inflammatory, anti-neoplastic and cerebroprotective properties (Hickman \& Whitehead, 2012). It undergoes post-translational modification and multimerisation prior to secretion (Simpson \& Whitehead, 2010) and circulates in multimers termed low molecular weight (LMW; trimer and hexamer) and high molecular weight (HMW; 12- to 18mers) (Hickman \& Whitehead, 2012; Tsao, 2013). In diseases such as obesity and type 2 diabetes, adiponectin levels are decreased and this reflects a selective reduction in the levels of the HMW multimers. The HMW multimers are more metabolically active than LMW and are more closely correlated with health and disease than the total levels (Hickman \& Whitehead, 2012; Pajvani et al., 2004). Therefore, estimation of the HMW adiponectin in circulation is of greater clinical relevance. In light of this, there have been several studies examining the stability of total and HMW adiponectin under a range of laboratory processing conditions. Such investigations have demonstrated that both total (Suominen, 2004) and HMW adiponectin (Sattar et al., 2008; Schraw, Wang, Halberg, Hawkins, \& Scherer, 2008) are relatively stable in serum and plasma when subjected to multiple freeze-thaw cycles. However, the effect of pre-processing conditions such as the temperature and length of time that a blood sample may be stored and transported prior to centrifugation, separating serum or plasma from cells and subsequent storage of serum or plasma is still unclear. Total adiponectin has been shown to be stable for up to $36 \mathrm{~h}$ in Styrofoam containers containing ice packs prior to centrifugation in EDTA and sodium heparin samples (Pischon, Hotamisligil, \& Rimm, 2003). However, the effects of processing delays and prolonged blood sample storage on HMW adiponectin specifically have not been investigated to our knowledge. We hypothesise that variation in serum or plasma separation from cells post storage at different temperature and length of time may effect the concentration of adiponectin in serum and plasma. This pilot study aimed to investigate the stability of total and HMW adiponectin in EDTA plasma and serum samples, stored for $6 \mathrm{~h}$ and $72 \mathrm{~h}$ at $4{ }^{\circ} \mathrm{C}$ and $6 \mathrm{~h}$ at room temperature (RT), measured using commercially available enzyme-linked immunosorbent assays (ELISAs) that specifically detect monomeric or HMW adiponectin.

\section{Materials and Methods}

\subsection{Subjects}

This prospective, observational pilot study recruited eight healthy participants with informed written consent in accordance with the principles of the Declaration of Helsinki and requirements of the Princess Alexandra Hospital Human Research Ethics Committee. All participants were non-smoking, lean (body mass index calculated as weight (kilograms) / height (metres) ${ }^{2}$; range between $20-25 \mathrm{~kg} / \mathrm{m}^{2}$ ) and with no history of liver, metabolic, kidney or cardiovascular dysfunction.

\subsection{Processing of Serum and Plasma Samples}

At a single time-point (between 7am-8am) fasting blood ( $>8 \mathrm{~h}$ overnight fast) was drawn into 8 vacutainer tubes (4 EDTA and 4 serum per participant for analysis of plasma (4 x EDTA tubes - Cat\# 454023, clot activator tubes Cat\#456071, Greiner Bio-One. Kremsmunster, Austria), respectively. Tubes were then either processed with minimal storage (ideal) or following storage at room temperature (RT $24^{\circ} \mathrm{C}$; uncentrifuged on bench top) for $6 \mathrm{~h}$ or after storage at $4^{\circ} \mathrm{C}$ for $6 \mathrm{~h}$ and $72 \mathrm{~h}$ respectively. Comparative or 'ideal' processing involved a maximum of 15 min storage at $4^{\circ} \mathrm{C}$ followed by centrifugation at $3000 \mathrm{rpm}$ at RT for $10 \mathrm{~min}$. Samples were then aliquoted into Eppendorf tubes and stored at $-80^{\circ} \mathrm{C}$ for 1 month until analysis. Samples stored in vacutainer tubes for $6 \mathrm{~h}$ at $\mathrm{RT}$ or for $6 \mathrm{~h}$ or $72 \mathrm{~h}$ at $4^{\circ} \mathrm{C}$ prior to centrifugation were processed as per ideal conditions (described above) to allow for comparison of the effects of delayed processing. Samples were all analysed in duplicate and 3 internal controls were incorporated on each plate.

\subsection{Adiponectin Measurement}

Total and HMW adiponectin were analysed by antibody specific based assays (R\&D Systems, Minneapolis, MN, USA). In-house intra- and inter-assay CVs were $6.1 \%$ \& $14.1 \%$ and $3.2 \% \& 8.7 \%$ for total and HMW adiponectin respectively.

\subsection{Statistical Analysis}

Data were normally distributed (Kolmogorov-Smirnov Test) and are reported as means $( \pm \mathrm{SD})$ or mean differences $(95 \%$ CI). Paired student t-tests were used to compare differences between the comparative (ideal) and test conditions (for total and HMW adiponectin) for both the serum and plasma sample types at identical time points and between the different storage conditions (ideal, $72 \mathrm{~h}$ at $4^{\circ} \mathrm{C}, 6 \mathrm{~h}$ at $4{ }^{\circ} \mathrm{C}$ and $6 \mathrm{~h}$ at RT). To account for multiple comparisons (maximum of four comparisons) statistical significance was set at $\mathrm{p}<0.0125$ (two-tailed). All analyses were performed using IBM SPSS Statistics for Windows (version 22.0, Armonk, NY: IBM Corp). A greater than 15\% difference in 
samples was deemed clinically significant as this is a change typically observed in studies with drug therapy targets (Gaich et al., 2013; Phillips et al., 2009).

\section{Results}

The participants (male $\mathrm{n}=4$; female $\mathrm{n}=4$ ) had a mean body mass index $22.7( \pm 2.2) \mathrm{kg} / \mathrm{m}^{2}$ and mean age $32.8( \pm 8.0)$ years.

\subsection{Effect of Sample Type and Prolonged Storage on the Stability of Total and HMW Adiponectin}

A. $72 \mathrm{~h}$ storage at $4^{\circ} \mathrm{C}$

Table 1 summarises the total and HMW adiponectin results in serum and plasma under ideal conditions and after a 72 hour delay in processing. Under comparative or "ideal" blood handling conditions serum yielded significantly higher total and HMW adiponectin concentrations than plasma (mean difference: $-1.3 \mu \mathrm{g} / \mathrm{mL}$ [95\% CI: $-1.6,-1.0]$, $\mathrm{p}<0.001$; and, $-0.6 \mu \mathrm{g} / \mathrm{mL}$ [95\% CI: $-0.7,-0.5], \mathrm{p}<0.001$, respectively). Prolonged blood storage, $72 \mathrm{~h}$ at $4{ }^{\circ} \mathrm{C}$, resulted in a decrease in serum total adiponectin levels compared with ideal conditions (mean difference: $-1.4 \mu \mathrm{g} / \mathrm{mL}$ [95\% CI: -2.0 , $-0.8], \mathrm{p}=0.001$ ), whereas serum HMW adiponectin concentrations were similar (mean difference: $-0.2 \mu \mathrm{g} / \mathrm{mL}$ [95\% CI: $-0.5,0.0], p=0.074)$. In contrast, in plasma, total adiponectin concentrations were not statistically significantly different after $72 \mathrm{~h}$ storage compared with ideal conditions (mean difference: $-0.3 \mu \mathrm{g} / \mathrm{mL}$ [95\% CI: $-1.5,0.8]$, $\mathrm{p}=0.511$ ) whereas HMW adiponectin levels significantly decreased after $72 \mathrm{~h}$ storage at $4^{\circ} \mathrm{C}$ (mean difference: $-0.6 \mu \mathrm{g} / \mathrm{mL}$ [95\%CI: -0.9 , $-0.2], \mathrm{p}=0.007$ ). The significant differences observed between serum and plasma for total and HMW adiponectin concentrations under ideal handling remained after $72 \mathrm{~h}$ of storage at $4^{\circ} \mathrm{C}$ for HMW adiponectin only (mean difference: $-0.9 \mu \mathrm{g} / \mathrm{ml}[95 \% \mathrm{CI}:-1.4,-0.4], \mathrm{p}=0.003)$.

Table 1. Total and high molecular weight (HMW) measured in serum and plasma. Measurements under ideal handling conditions or after $72 \mathrm{~h}$ delay in sample processing $(\mathrm{n}=8)$.

\begin{tabular}{c|c|c|c|c|c|c|c|c}
\hline & \multicolumn{4}{|c|}{ Total Adiponectin $(\boldsymbol{\mu g} / \mathbf{m L})$} & \multicolumn{4}{c}{ HMW Adiponectin $(\boldsymbol{\mu g} / \mathbf{m L})$} \\
\cline { 2 - 9 } & Ideal & $\mathbf{7 2} \mathbf{~ h}$ & $\mathbf{p}^{\mathbf{a}}$ & Mean \% difference & Ideal & $\mathbf{7 2} \mathbf{~ h}$ & $\mathbf{p}^{\mathbf{a}}$ & Mean \% difference \\
\hline Serum & $7.2 \pm 1.9$ & $5.8 \pm 2.0$ & 0.001 & 19.4 & $4.2 \pm 1.4$ & $3.9 \pm 1.6$ & 0.074 & 7.1 \\
\hline Plasma & $6.0 \pm 1.8^{*}$ & $5.6 \pm 2.2$ & 0.511 & 6.7 & $3.6 \pm 1.3^{*}$ & $3.0 \pm 1.3$ & 0.007 & 16.7 \\
\hline
\end{tabular}

(Data are mean $\pm \mathrm{SD},{ }^{a} \mathrm{p}$-value comparing ideal handling and after $72 \mathrm{~h}$ delay (paired t-tests), ${ }^{*} \mathrm{p}<0.01$ (paired $\mathrm{t}$-test comparing serum and plasma), Mean $\%$ difference calculated as the mean percent change between ideal and $72 \mathrm{~h}$ storage conditions in serum and plasma.)

B. $6 \mathrm{~h}$ storage at $4^{\circ} \mathrm{C}$ and Room Temperature (RT)

Having established there was a significant decrease in serum total adiponectin concentrations after $72 \mathrm{~h}$ blood storage at $4{ }^{\circ} \mathrm{C}$ we then investigate whether a $6 \mathrm{~h}$ delay at $4^{\circ} \mathrm{C}$ or at RT might also affect total adiponectin concentrations, as these conditions may reflect those expected to occur in a clinical setting.

Compared with ideal conditions, a significant decrease in serum total adiponectin concentrations was observed when stored for $6 \mathrm{~h}$ at $4^{\circ} \mathrm{C}$ (mean difference: $-0.7 \mu \mathrm{g} / \mathrm{ml}$ [95\% CI: $\left.-1.1,-0.4\right], \mathrm{p}=0.002$ ) and for $6 \mathrm{~h}$ at RT (mean difference: $-0.8 \mu \mathrm{g} / \mathrm{ml}$ [95\% CI: $-1.3,-0.4], \mathrm{p}=0.003$ ), similar to that observed after blood storage for $72 \mathrm{~h}$ (Figure 1).

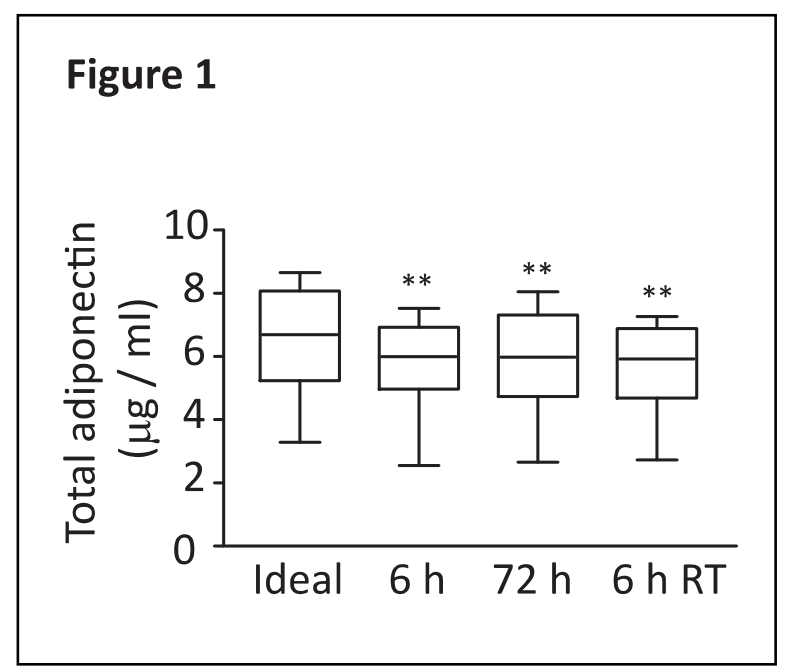

Figure 1. Effects of time and temperature on measurement of total adiponectin levels in serum 
Total adiponectin levels after delay in sample processing at $4^{\circ} \mathrm{C}$ for 6 or $72 \mathrm{~h}$, or at RT for $6 \mathrm{~h}(\mathrm{n}=8$; each sample measured in duplicate on $\mathrm{x} 2$ separate ELISA kits; paired student $\mathrm{t}$-tests were used to compare differences between the comparative (ideal) and test condition; **p<0.010). (Ideal - refers to comparative handling conditions; $6 \mathrm{~h}$ - blood sample stored for 6 hours at $4^{\circ} \mathrm{C} ; 72 \mathrm{~h}$ - blood sample stored for 72 hours at $4^{\circ} \mathrm{C} ; 6 \mathrm{hRT}$ - blood sample stored for 6 hours at room temperature.)

\section{Discussion}

This findings of this study suggests that delays in processing of blood samples may result in clinically significant lower concentrations of total adiponectin in serum and lower concentrations of HMW adiponectin in plasma using the describe ELISA assay. Reductions in total adiponectin concentrations were detectable both when blood tube storage was at room temperature and when refrigerated at 4 degrees Celsius.

The development of both total adiponectin and HMW specific antibodies has provided investigators with the opportunity to explore the relationship between adiponectin profiles and disease in large cohorts and or longitudinal studies that was hitherto unrealistic. This has also prompted several investigations exploring the influence of sample-handling and storage variation on the stability of total and HMW adiponectin (Sattar et al., 2008; Schraw et al., 2008; Suominen, 2004). Such studies show that both total and HMW adiponectin are stable in serum or plasma when subjected to multiple freeze-thaw cycles (Sattar et al., 2008; Schraw et al., 2008; Suominen, 2004). Furthermore, total adiponectin has been reported to be stable in blood for up to $36 \mathrm{~h}$, in Styrofoam containers containing ice packs, prior to processing for measurement in plasma (Pischon et al., 2003). In this study we extended the pre-analytical storage conditions, which is more in line with what occurs in remote collection centres using EDTA plasma and serum samples for total adiponectin as well as the more metabolically active HMW multimers. The data showed that the total and HMW adiponectin concentrations were affected by the pre-analytical processes.

Delays in processing blood samples had modest but significant and differential effects on the concentrations of total and HMW adiponectin in serum and plasma respectively. In serum, there was a mean $20 \%$ reduction in total adiponectin concentrations following extended $\left(72 \mathrm{~h}\right.$ at $\left.4^{\circ} \mathrm{C}\right)$ storage of blood whilst concentrations of HMW adiponectin were relatively unaffected. These observations suggest enhanced stability of HMW adiponectin relative to LMW adiponectin in serum, at least under these handling conditions. One possibility is that the extensive post-translational modifications (PTMs) required for the efficient multimerisation and secretion of HMW adiponectin enhance its stability. Such PTMs include hydroxylation and glycosylation of conserved lysines situated within the collagenous stalk of adiponectin (Richards et al., 2006; Wang et al., 2006) and, consistent with the above, these have been shown to make HMW adiponectin refractory to digestion by proteinase K (Peake, Hughes, Shen, \& Charlesworth, 2007). Interestingly, in serum we also observed a similar decrease in total adiponectin concentrations following a $6 \mathrm{~h}$ delay at either $4^{\circ} \mathrm{C}$ or RT, suggesting that time, rather than temperature, is of the essence when processing blood samples for total adiponectin analysis in serum.

Furthermore the sample type had an influence on the stability as after $72 \mathrm{~h}$ delay in sample processing, total adiponectin decreased to a greater extent in serum than in plasma, and in contrast HMW adiponectin decreased to a greater extent in plasma but not in serum. In addition to PTMs, calcium has been reported as important for the formation (Yu, Zhang, Wang, \& Qin, 2013) and stability (Banga et al., 2008) of HMW adiponectin. Using differential centrifugation and SDS-PAGE/Western blot to analyse adiponectin multimer profiles, Banga and colleagues demonstrated marked dissociation of HMW to LMW multimers in EDTA plasma when compared with serum from four subjects (Banga et al., 2008). In comparison to these observations, we observed a smaller, albeit statistically significant and clinically meaningful, 15\% decrease in HMW adiponectin concentrations when blood samples were stored for $72 \mathrm{~h}$ in EDTA plasma tubes prior to processing. However we note the harsher forces that samples processed by sucrose gradient velocity sedimentation are subject to compared to the relatively mild conditions of an ELISA. That we observed no decrease in total plasma adiponectin levels after delayed processing of blood samples appears consistent with a report where total plasma adiponectin was unaffected following storage of blood samples as described by Pischon and colleagues (Pischon et al., 2003). In contrast Pischon and colleagues showed EDTA plasma samples led to an increase in total adiponectin levels of almost $20 \%(\mathrm{p}=0.05)$, in contrast to plasma samples collected in sodium-heparin, prompting the authors to suggest that the apparent increase in the presence of EDTA may reflect dissociation of the HMW adiponectin multimers resulting in enhanced detection of lower order multimers by the antibodies in the ELISA (Pischon et al., 2003). Collectively then, stability of the HMW multimers appears, at least in this small study, to be dependent on a variety of complementary factors including the degree of PTM and presence of calcium (Hickman \& Whitehead, 2012; Richards et al., 2006; Simpson \& Whitehead, 2010; Wang et al., 2006). Hence, the effect of perturbing any of these parameters is likely to affect multimer stability in a context-dependent manner. Given the number of PTMs is variable between individuals and across multimers (Richards et al., 2006; Wang et al., 2006), and 
that calcium content may also vary, there is likely to be some degree of variability between subjects although this study was not designed to address this question.

The results of this pilot study suggest that adhering to ideal (standardised and optimised) processing conditions is desirable in studies looking for differences in both total and HMW adiponectin concentrations. If that is not achievable, from our results the option which is least susceptible to differences in sample handling would be to measure HMW adiponectin in serum. For total adiponectin it is possible to store plasma samples for $6-72 \mathrm{~h}$ at $4^{\circ} \mathrm{C}$ prior to processing to reduce variability. Based on the current findings we suggest that sample processing conditions should be optimised and standardised before commencing studies and include tight protocols around time and temperature conditions when blood samples need to be handled by different laboratories or transported between sites. Protocols which reduce handling time are most recommended but consistency across all sample collection is most critical regardless of protocol.

A limitation of this pilot study is the small number of participants, all of whom were lean and healthy. Even with this small sample we observed statistically significant and clinically meaningful differences between most sample conditions indicating that larger studies in more heterogeneous groups are warranted. For comparisons where non-significant differences were observed, the confidence intervals could not conclusively rule out meaningful effects as unlikely, with the exception of the comparison of HMW adiponectin between ideal and $72 \mathrm{~h}$ delay in serum. While the degree of variation in stability of adiponectin between individuals is unknown, as mentioned above, given that PTMs contribute to adiponectin multimerisation and stability and that the number of PTMs such as glycosylation are reduced in diseases such as type 2 diabetes (Richards et al., 2006; Wang et al., 2006), further and more extensive studies are required to determine whether stability is comparable across disease populations.

Notwithstanding, this pilot study demonstrates that delays in processing of blood samples collected for analysis, be it plasma or serum, may result in decreases in total and or HMW adiponectin measures hence consistency at this step is recommended and delays should, wherever possible, be avoided.

In conclusion, pre-analytical conditions variations, such as delay in processing blood samples, may result in a reduced concentration of total and HMW adiponectin in serum and plasma respectively. Larger studies designed to identify the effect of different pre-analytical conditions in blood handling procedures in large multi-site clinical trials are warranted.

\section{Acknowledgements}

This work was supported by an Australian National Health and Medical Research Council Scholarship (FJR), a University of Queensland Post-Graduate Scholarship (SK), a National Breast Cancer Foundation Fellowship (MMR), and an Australian National Health and Medical Research Council Fellowship (JPW).

\section{References}

Banga, A., Bodles, A. M., Rasouli, N., Ranganathan, G., Kern, P. A., \& Owens, R. J. (2008). Calcium is involved in formation of high molecular weight adiponectin. Metab Syndr Relat Disord, 6(2), 103-111. http://dx.doi.org/10.1089/met.2007.0033

Gaich, G., Chien, J. Y., Fu, H., Glass, L. C., Deeg, M. A., Holland, W. L., . . Moller, D. E. (2013). The effects of LY2405319, an FGF21 analog, in obese human subjects with type 2 diabetes. Cell Metab, 18(3), 333-340. http://dx.doi.org/10.1016/j.cmet.2013.08.005

Hickman, I. J., \& Whitehead, J. P. (2012). Structure, signalling and physiologic role of adiponectin-dietary and exercise- related variations. Curr Med Chem, 19(32), 5427-5443. http://dx.doi.org/10.2174/092986712803833155

Keustermans, G. C., Hoeks, S. B., Meerding, J. M., Prakken, B. J., \& de Jager, W. (2013). Cytokine assays: an assessment of the preparation and treatment of blood and tissue samples. Methods, 61(1), 10-17. http://dx.doi.org/10.1016/j.ymeth.2013.04.005

Mechanic, L., Mendez, A., Merrill, L., Rogers, J., Layton, M., Todd, D., . . Moye, J. (2013). Planned variation in preanalytical conditions to evaluate biospecimen stability in the National Children's Study (NCS). Clin Chem Lab Med, 5l(12), 2287-2294. http://dx.doi.org/10.1515/cclm-2013-0454

Oddoze, C., Lombard, E., \& Portugal, H. (2012). Stability study of 81 analytes in human whole blood, in serum and in plasma. Clin Biochem, 45(6), 464-469. http://dx.doi.org/10.1016/j.clinbiochem.2012.01.012

Pajvani, U. B., Hawkins, M., Combs, T. P., Rajala, M. W., Doebber, T., Berger, J. P., . . S Scherer, P. E. (2004). Complex distribution, not absolute amount of adiponectin, correlates with thiazolidinedione-mediated improvement in insulin sensitivity. J. Biol. Chem., 279(13), 12152-12162. http://dx.doi.org/10.1074/jbc.M311113200 
Peake, P. W., Hughes, J. T., Shen, Y., \& Charlesworth, J. A. (2007). Glycosylation of human adiponectin affects its conformation and stability. J Mol Endocrinol, 39(1), 45-52. http://dx.doi.org/10.1677/JME-07-0030

Phillips, S. A., Kung, J., Ciaraldi, T. P., Choe, C., Christiansen, L., Mudaliar, S., \& Henry, R. R. (2009). Selective regulation of cellular and secreted multimeric adiponectin by antidiabetic therapies in humans. Am J Physiol Endocrinol Metab, 297(3), E767-773. http://dx.doi.org/10.1152/ajpendo.00378.2009

Pischon, T., Hotamisligil, G. S., \& Rimm, E. B. (2003). Adiponectin: stability in plasma over 36 hours and within-person variation over 1 year. Clin Chem, 49(4), 650-652. http://dx.doi.org/10.1373/49.4.650

Richards, A. A., Stephens, T., Charlton, H. K., Jones, A., Macdonald, G. A., Prins, J. B., \& Whitehead, J. P. (2006). Adiponectin multimerization is dependent on conserved lysines in the collagenous domain: evidence for regulation of multimerization by alterations in posttranslational modifications. Mol Endocrinol, 20(7), 1673-1687. http://dx.doi.org/10.1210/me.2005-0390

Sattar, N., Watt, P., Cherry, L., Ebrahim, S., Davey Smith, G., \& Lawlor, D. A. (2008). High molecular weight adiponectin is not associated with incident coronary heart disease in older women: a nested prospective case-control study. J. Clin. Endocrinol. Metab., 93(5), 1846-1849. http://dx.doi.org/10.1210/jc.2007-2603

Schraw, T., Wang, Z. V., Halberg, N., Hawkins, M., \& Scherer, P. E. (2008). Plasma adiponectin complexes have distinct biochemical characteristics. Endocrinology, 149(5), 2270-2282. http://dx.doi.org/10.1210/en.2007-1561

Simpson, F., \& Whitehead, J. P. (2010). Adiponectin--it's all about the modifications. Int. J. Biochem. Cell. Biol., 42(6), 785-788. http://dx.doi.org/10.1016/j.biocel.2009.12.021

Suominen, P. (2004). Evaluation of an enzyme immunometric assay to measure serum adiponectin concentrations. Clin. Chem., 50(1), 219-221. http://dx.doi.org/10.1373/clinchem.2003.025833

Tsao, T. S. (2013). Assembly of adiponectin oligomers. Rev. Endocr. Metab. Disord., http://dx.doi.org/10.1007/s11154-013-9256-6

Wang, Y., Lam, K. S., Chan, L., Chan, K. W., Lam, J. B., Lam, M. C., . . X Xu, A. (2006). Post-translational modifications of the four conserved lysine residues within the collagenous domain of adiponectin are required for the formation of its high molecular weight oligomeric complex. J. Biol. Chem., 281(24), 16391-16400. http://dx.doi.org/10.1074/jbc.M513907200

Yu, D., Zhang, C., Wang, H., \& Qin, P. (2013). Characterization of the weak calcium binding of trimeric globular adiponectin. Cell Biochem. Funct., 31(4), 338-343. http://dx.doi.org/10.1002/cbf.2906

Zimmerman, L. J., Li, M., Yarbrough, W. G., Slebos, R. J., \& Liebler, D. C. (2012). Global stability of plasma proteomes for mass spectrometry-based analyses. Mol. Cell Proteomics, 11(6), M111 014340. http://dx.doi.org/10.1074/mcp.M111.014340

\section{Copyrights}

Copyright for this article is retained by the author(s), with first publication rights granted to the journal.

This is an open-access article distributed under the terms and conditions of the Creative Commons Attribution license (http://creativecommons.org/licenses/by/4.0/). 